\title{
Electrochemical Behaviour and Adsorptive Stripping Voltammetric Determination of Cyclophosphamide
}

\author{
PRIYANKA SINHA, SACHIN DOI and D. K. SHARMA* \\ Electrochemical Sensor Research Laboratory, \\ Department of Chemistry, University of Rajasthan, Jaipur (Rajasthan)-302004, India \\ sharmadkuor@gmail.com
}

Received 26 May 2017 / Accepted 20 July 2017

\begin{abstract}
Electrochemical behaviour of anticancer medication cyclophosphamide was studied in BR buffer of pH 3.0 at glassy carbon electrode using cyclic voltammetry. Cyclophosphamide gave one well defined irreversible reduction peak at potential $-1.4 \mathrm{~V}$ v/s $\mathrm{Ag} / \mathrm{AgCl}$ reference electrode. The reduction was diffusion controlled and all kinetic parameters were calculated and a reduction mechanism was proposed based on the observed experimental data. Furthermore, differential pulse cathodic adsorptive stripping voltammetry (DPCAdSV) was optimized for determination of cyclophosphamide in bulk form and human urine as biological sample. Good linearity range and obtained LOD and LOQ of $1.1 \times 10^{-6} \mathrm{M}$ and $3.67 \times 10^{-6} \mathrm{M}$ respectively indicated about the good sensitivity of developed method.
\end{abstract}

Keywords: Cyclophosphamide, Cyclic voltammetry, Differential pulse cathodic adsorptive stripping voltammetry, Diffusion controlled, LOD and LOQ

\section{Introduction}

Cyclophosphamide (CYP), chemically 2-[bis(2-chloroethyl)amino]tetrahydro-2H-1,3,2oxazaphosphorine 2-oxide is nitrogen mustard-derivative alkylating agent (Figure 1), used as medication in chemotherapy, as immunosuppressant and falls in the category of antineoplastic agents ${ }^{1,2}$. As an immune suppressor it is used in nephrotic syndrome and following organ transplant ${ }^{3}$. CYP is believed to exert its cytotoxic effects through the covalent linkage of alkyl groups to DNA ${ }^{4}$. The main site of alkylation on DNA has been identified as the N-7 position of guanine for the nitrogen mustards ${ }^{5,6}$. Monofunctional alkylating agents are considered to be less cytotoxic as compared to the bifunctional alkylating agents. This is due to their cross linking ability, in which one arm forms covalent bond with the nucleotide while other reactive arm is free to bind with low molecular weight molecules such as water and glutathione or with macromolecule like DNA and protein ${ }^{7}$.

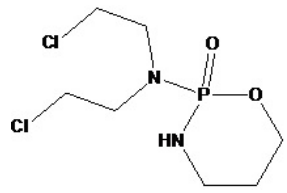

Figure 1. Chemical structure of cyclophosphamide 
The dosage of CYP is quite crucial to health as it is not excreted completely from body and has a tendency to get accumulated, so cells become drug resistant and response to the drug action decreases. This is why, a number of techniques have been introduced for determination of CYP in human serum including pencil graphite and hanging mercury drop electrodes ${ }^{8}$, electrochemical sensing platform based on molecularly imprinted polymer decorated N,S co-doped activated grapheme $^{9}$, HPLC method ${ }^{10}$, GC-MS and solid phase extraction ${ }^{11}$, reverse phase high performance liquid chromatographic method ${ }^{12}$, colorimetric determination ${ }^{13}$ and spectrofluorimetric method ${ }^{14}$. These methods include tedious steps along with time consuming extraction process prior to the determination. The widespread use of this compound and the need for clinical and pharmacological studies require fast and sensitive analytical techniques to assay the drug in Human urine. Unlike these methods voltammetry is a simple, low-cost technique with good accuracy, precision and great detection limit. Furthermore, detailed electrode kinetics and voltammetric determination of CYP in human urine with GCE has not been reported till date. Thus, the present paper reports a new voltammetric method for detailed study of CYP's electrochemical behavior and determination in bulk form and in human urine as biological sample.

\section{Experimental}

All electrochemical measurements were performed using a model 1230 A [SR 400] electrochemical analyzer (CHI instrument, USA). Controlled potential coulometric experiments were carried out on model 760 electrochemical workstation (CHI Instrument). A cell system incorporating three electrodes (glassy carbon as working electrode, $\mathrm{Ag} / \mathrm{AgCl}$ as reference and $\mathrm{Pt}$ as counter electrode) was used throughout the experiment. All $\mathrm{pH}$ metric measurements were performed using CHINO digital $\mathrm{pH}$ meter fitted with a glass electrode standardized with buffers of known $\mathrm{pH}$. All experiments were carried out at standard temperature of $25^{\circ} \mathrm{C}$.

\section{Materials and methods}

CYP was obtained in its anhydrous pure form from United Biotech Pvt. Ltd. and was used as it was. A standard solution of concentration $2.5 \times 10^{-3} \mathrm{M}$ (E.C. $2.5 \times 10^{-4} \mathrm{M}$ ) was prepared by dissolving $0.016 \mathrm{~g}$ of drug in $25 \mathrm{~mL}$ water. Voltammograms were recorded by taking aliquots of standard solution in Britton Robinson Buffer. All chemicals used were of analytical grade and obtained from Sigma-Aldrich. Double distilled deionized water, obtained from laboratory distillation assembly was used for making solutions and throughout the voltammetric studies. All solutions were protected from light and were used within $24 \mathrm{~h}$ to avoid decomposition. However, electrochemical response of sample solutions recorded after preparation did not show any significant change in the studies.

An aliquot of the solution was then analyzed according to the proposed voltammetric procedure after diluting its appropriate volume with $9 \mathrm{~mL}$ of BR buffer in electrochemical cell. The effective concentration (E.C.) of the sample in the electrochemical cell was calculated as (Concentration $(\mathrm{M})$ of analyte solution $\times$ Volume $(\mathrm{mL})$ of analyte solution added in the cell)/Total volume of solution in the cell. The concentration mentioned throughout the research work is in terms of E.C.

\section{Preparation of spiked urine samples}

Drug-free human urine, obtained from healthy volunteers was stored frozen until assay. Aliquots of urine were transferred into series of centrifugation tubes and aliquots of CYP stock solution of bulk and pharmaceutical formulations were added separately to get the final concentration. All the solutions were mixed well using a vortex mixer. After vortexing for $30 \mathrm{~s}$, the mixture was then centrifuged for $10 \mathrm{~min}$ at $4000 \mathrm{rpm}$ in order to eliminate any residues. 
Contents of the centrifugation tubes were transferred quantitatively into $10 \mathrm{~mL}$ measuring flasks. Tubes were washed with water, and the washings were transferred into the same measuring flask. The final solutions for recording voltammograms were prepared by adding BR buffer solution to the measuring flask and transferring the contents of flask into voltammetric cell.

\section{Pretreatment of glassy carbon electrode and voltammetric procedure}

The working electrode GCE was polished with $0.08 \mu \mathrm{m}$ Alumina in water slurry and was subjected for sonication for a short duration of $10 \mathrm{~s}$ prior to each experiment in order to remove all impurities remained onto the surface of the electrode and further dried at $30{ }^{\circ} \mathrm{C}$ in oven. A continuous stream of Nitrogen (99\% pure) was passed through the solutions for deoxygenation before each voltammetric measurement.

\section{Results and Discussion}

\section{Electrochemical behavior of CYP}

The electrochemical behavior of CYP at GCE was studied using cyclic voltammetry (CV), Controlled potential coulometry (CPC) and differential pulse cathodic adsorptive stripping voltammetry (DPCAdSV). In all electrochemical methods, CYP gave one well-defined cathodic peak in BR buffer of pH 3.0 at GCE.

\section{Cyclic voltammetric behaviour}

CYP gave one well defined reduction peak at a potential of $-1.4 \mathrm{~V}$ when cyclic voltammograms were recorded by applying a negative going scan from $0.0 \mathrm{~V}$ to $-1.8 \mathrm{~V}$ versus $\mathrm{Ag} / \mathrm{AgCl}$ reference electrode in BR buffer of $\mathrm{pH} 3.0$ at GCE.

\section{Effect of scan rate}

The influences of the potential scan rate on cathodic peak current (Ip) and cathodic peak potential (Ep) were investigated for the solution in the $40-180 \mathrm{mVs}^{-1}$ range as depicted in Figure 2. The peak potential shifted towards more negative values with increasing scan rate following the criterion of irreversibility according to Nicholson theory ${ }^{15}$. For a diffusion controlled process, peak current is directly proportional to the square root $\left(\operatorname{Ip} \alpha v^{1 / 2}\right)$ of scan rate while a direct proportionality of peak current with scan rate (Ip $\alpha v$ ) implies about the adsorption controlled rate determining step of the redox process ${ }^{16,17}$.

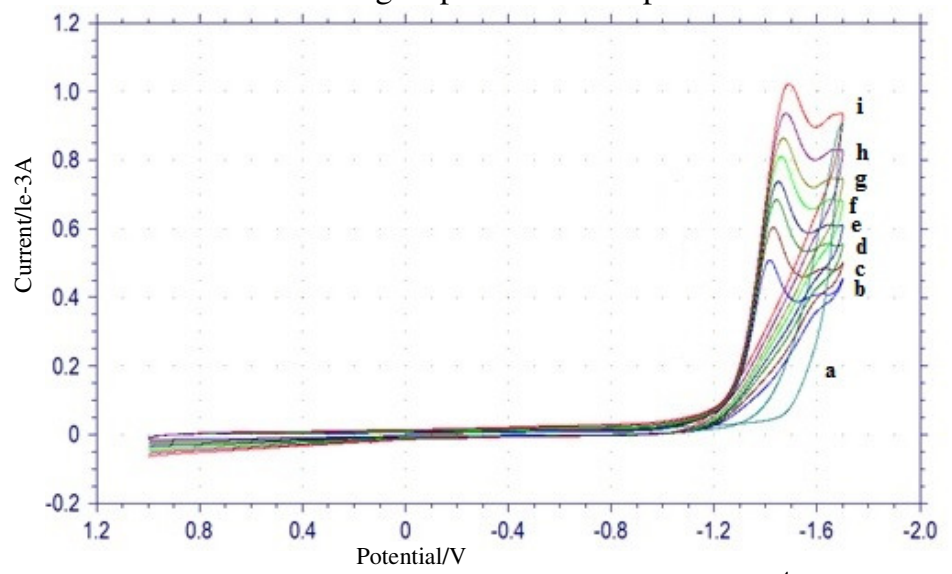

Figure 2. Cyclic voltammograms of CYP (Concentration $2.5 \times 10^{-4} \mathrm{M}$ ) at different scan rates (a) blank (b) $40 \mathrm{mV} / \mathrm{s} \mathrm{(c)} 60 \mathrm{mV} / \mathrm{s}$ (d) $80 \mathrm{mV} / \mathrm{s}$ (e) $100 \mathrm{mV} / \mathrm{s}$ (f) $120 \mathrm{mV} / \mathrm{s} \mathrm{(g)} 140 \mathrm{mV} / \mathrm{s}$ (h) $160 \mathrm{mV} / \mathrm{s}(\mathrm{i}) 180 \mathrm{mV} / \mathrm{s}$ at $\mathrm{pH} 3.0$ in BR buffer 
A linear plot between peak current $v s$. square root of scan rate indicated about diffusive nature of electrode process consistent with the Randles-Sevcik equation:

Ip $=\left(2.99 \times 10^{5}\right) n\left[{\alpha n^{\prime}}^{\prime}\right]^{1 / 2} \mathrm{~A}$ Co Do ${ }^{1 / 2} v^{1 / 2}$, where $n$ is the number of electrons exchanged in reduction, $\mathrm{n}^{\prime}$ is the number of electrons involved in the rate determining step, $\alpha$ is the charge transfer coefficient, $\mathrm{A}\left(\mathrm{cm}^{2}\right)$ is the apparent surface area of the electrode, $\mathrm{Co}(\mathrm{M})$ is the concentration of the electroactive species, $\operatorname{Ip}(\mu \mathrm{A})$ is the cathodic peak current, $\operatorname{Do}\left(\mathrm{cm}^{2} \mathrm{~s}^{-1}\right)$ is the diffusion coefficient of the electroactive species and $v\left(\mathrm{mV} \mathrm{s}^{-1}\right)$ is the scan rate. The corresponding regression equation of plot between Ip and $v^{1 / 2}$ in Figure 3 is:

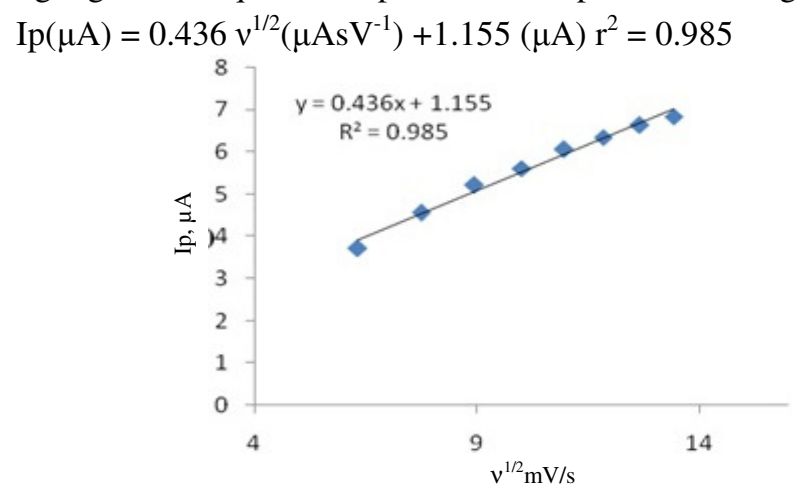

Figure 3. Plot of peak current $\left(\mathrm{I}_{\mathrm{p}}\right)$ versus square root of scan rate $\left(v^{1 / 2}\right)$ from voltammogram in Figure 2 for CYP in $2.5 \times 10^{-4} \mathrm{M}$ concentration in BR Buffer of $\mathrm{pH} 3.0$

The linear regression equation related to the plot of logarithm of peak current $\mathrm{Ip}(\mu \mathrm{A})$ versus $\log$ arithm of scan rate $(\mathrm{mV} / \mathrm{s})$ was found to be $\log (\mathrm{Ip})=0.402 \log v-0.061$ with $r^{2}=0.990$ (Figure 4). Slope of this curve $(0.402 \log$ Ip/log $v)$ is very close to the theoretical value of 0.5 for a pure diffusion controlled process ${ }^{18}$. Hence the reduction process was termed to be under diffusion control.

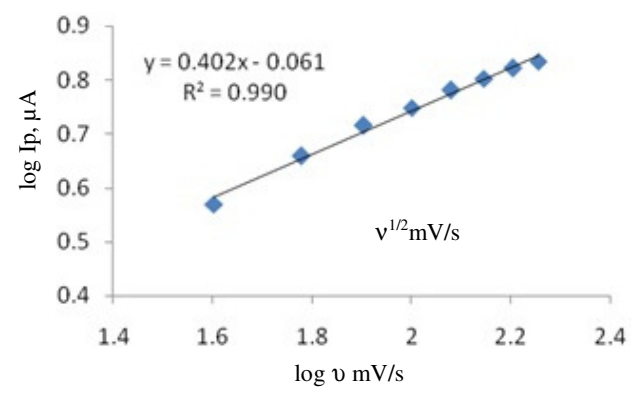

Figure 4. Plot of logarithm of peak current (log Ip) versus logarithm of scan rate (log v) from voltammogram in Figure 2 for CYP in $2.5 \times 10^{-4} \mathrm{M}$ concentration in BR Buffer of $\mathrm{pH} 3.0$

\section{Determination of surface area and reduction mechanism}

The effective surface area of glassy carbon electrode was calculated by recording cyclic voltammograms of $1 \mathrm{mM} \mathrm{K} \mathrm{K}_{3} \mathrm{Fe}(\mathrm{CN})_{6}$ at $100 \mathrm{mV} / \mathrm{s}$ scan rate using $0.1 \mathrm{M} \mathrm{KCl}$ as the supporting electrolyte. For the reversible redox reaction of the $\mathrm{Fe}(\mathrm{CN})_{6}{ }^{3-} / \mathrm{Fe}(\mathrm{CN})_{6}{ }^{4-}$ couple the peak potential appeared at $0.104 / 0.180 \mathrm{~V}$ for bare GCE. For a diffusion coefficient of $7.6 \times 10^{-6} \mathrm{~cm}^{2} / \mathrm{s}$ and total number of electrons (n) of $1,0.0247 \mathrm{~cm}^{2}$ was calculated as the effective area of electrode ${ }^{19}$. 


\section{Kinetics of reduction of CYP}

Determination of parameter [ $\alpha$ n']

For the reduction kinetics, the value of $\alpha n^{\prime}$ was calculated by the slope of graph between Ep and $\log v$ following that the slope is equal to $-2.303 \mathrm{RT} / 2 \alpha^{\prime} \mathrm{F}$ (Figure 5) according to the equation ${ }^{20}$.

$$
\mathrm{Ep}=\mathrm{E}^{0}-\frac{\mathrm{RT}}{\alpha \mathrm{n}^{\prime} \mathrm{F}}\left[0.78+\ln \left(\frac{\mathrm{D}_{0}^{1 / 2}}{\mathrm{k}_{\mathrm{S}}}\right)-0.5 \ln \frac{\mathrm{RT}}{\alpha \mathrm{n}^{\prime} \mathrm{F}}\right]-\left(\frac{\mathrm{RT}}{2 \alpha \mathrm{n}^{\prime} \mathrm{F}}\right) \ln v
$$

Where, $\mathrm{E}_{\mathrm{p}}$ is peak potential $(\mathrm{V}), \mathrm{E}^{\mathrm{o}}$ is formal potential $(\mathrm{V}), \mathrm{T}$ the temperature, $\alpha$ is the cathodic electron transfer coefficient, $\mathrm{n}^{\prime}$ is number of electrons involved in slowest step, $\mathrm{k}_{\mathrm{s}}$ is electrochemical heterogenous rate constant and $\mathrm{F}$ is the Faraday and rest parameters have their usual meanings.

The regression equation of graph between peak potential $\left(\mathrm{E}_{\mathrm{p}}\right)$ versus logarithm of scan rate $(\log v)$ (Figure 5) was found to be:

$$
\mathrm{Ep}(-\mathrm{V})=0.111 \log v+1.230(-\mathrm{V}) \mathrm{r}^{2}=0.968
$$

The value of $\alpha \mathrm{n}^{\prime}$ was calculated as 0.3 using equation 2 .

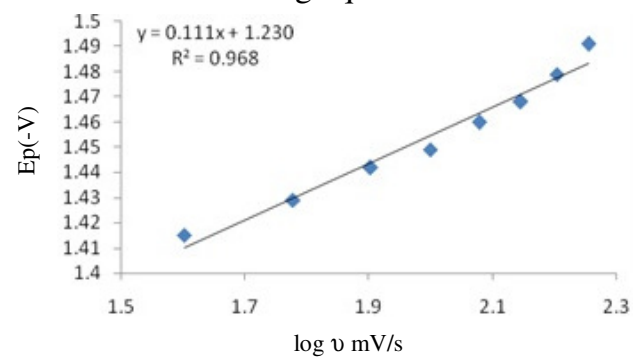

Figure 5. Plot of peak potential $\left(\mathrm{E}_{\mathrm{p}}\right)$ versus logarithm of scan rate $(\log v)$ for CYP in $2.5 \times 10^{-4} \mathrm{M}$ concentration in BR Buffer of $\mathrm{pH} 3.0$

Similar parameter was calculated by plotting a graph between $\ln I_{p}$ and $E p-E^{o}$ at different scan rates following that the slope is equal to $-\alpha n^{\prime} \mathrm{F} / \mathrm{RT}$ and intercept proportional to $\mathrm{k}^{\mathrm{O}}$ according to the equation ${ }^{21}$ :

$$
\mathrm{Ip}=0.227 \mathrm{nFACk}^{0} \mathrm{e}\left[-\alpha \mathrm{n}^{\prime} \mathrm{F}\left(\mathrm{Ep}-\mathrm{E}^{\mathrm{o}}\right) / \mathrm{RT}\right]
$$

Where $\mathrm{k}^{\mathrm{o}}$ is standard heterogenous rate constant, $\mathrm{E}^{\mathrm{o}}$ is formal potential and rest parameters have their usual meanings. Linear regression equation of corresponding plot between $\ln \mathrm{I}_{\mathrm{p}}$ and $\mathrm{Ep}-\mathrm{E}^{\mathrm{o}}$ is (Figure 6):

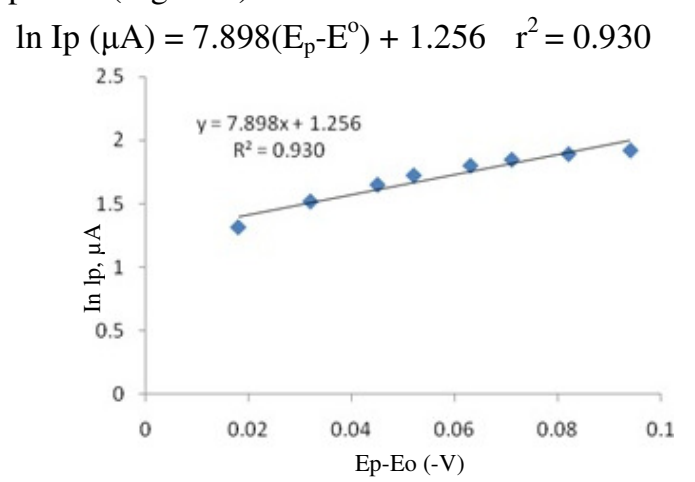

Figure 6. Plot of $\ln \mathrm{I}_{\mathrm{p}}$ versus $\mathrm{Ep}-\mathrm{E}^{\mathrm{o}}$ for $\mathrm{CYP}$ in $2.5 \times 10^{-4} \mathrm{M}$ concentration in BR buffer of $\mathrm{pH} 3.0$ 
The value of $\alpha n^{\prime}$ was calculated from the slope of the plot between $\ln I_{p}$ and $E_{p}-E^{o}$ and was found to be 0.20 . Thus values of $\alpha n^{\prime}$ determined from both aforementioned methods were nearly same and a mean value of 0.25 was used for the further considerations.

\section{Determination of total number of electrons}

The total number of electrons involved, was calculated by using CPC from the charge consumed by the desired concentration of CYP. For this purpose, $5 \mathrm{~mL}$ of $4 \mathrm{mg} \mathrm{mL}^{-1}$ solution of CYP was placed in the cell and exhaustive electrolysis was carried out at a potential of $-1.4 \mathrm{~V}$ against $\mathrm{Ag} / \mathrm{AgCl}$ reference electrode for $8 \mathrm{~h}$. Due to long time electrolysis it was assumed that the current efficiency was nearly $100 \%$ with a completion of reaction of 99.99\%. During the electrolysis, solutions were continuously stirred and purged with nitrogen. Total number of electrons participating was calculated using the equation $\mathrm{Q}=\mathrm{nFN}$, where $\mathrm{Q}$ is charge in coulombs, $\mathrm{F}$ is Faraday's constant and $\mathrm{N}$ is number of moles of the substrate. Total number of electrons involved in the reduction was calculated from controlled potential coulometric studies and was found to be 2 .

Determination of diffusion coefficient $\left(D_{o} \mathrm{~cm}^{2} / \mathrm{s}\right)$

Based on the data obtained, diffusion coefficient for reduction phenomena of CYP was calculated at $100 \mathrm{mV} / \mathrm{s}$ scan rate as $9.2 \times 10^{-5} \mathrm{~cm}^{2} / \mathrm{s}$ when $\mathrm{n}=2, \alpha \mathrm{n}^{\prime}=0.25, \mathrm{~A}=0.0247 \mathrm{~cm}^{2}$ and $\mathrm{C}=2.5 \times 10^{-7} \mathrm{~mol} / \mathrm{cm}^{3}$ using same Randles-Sevcik equation and a mean value was given. Hence the kinetic parameter, diffusion coefficient $\left(D_{0}\right)$ was calculated as $1.13 \times 10^{-14} \mathrm{~cm}^{2} / \mathrm{s}$ from Randles-Sevcik equation.

\section{Effect of $p H$}

The effect of $\mathrm{pH}$ on peak response at GCE was studied in BR buffer within the range 2.0 to 6.0. CYP reduced under acidic conditions and it was found that the proton participation was involved in the rate determining step of reduction process. At $\mathrm{pH}$ lower than 2.0, it may be attributed that the peak potential corresponding to the reduction of CYP is much negative than the Hydrogen evolution potential at GCE, so the peak response at the $\mathrm{pH}$ lower than 2.0 could not be observed. The optimized $\mathrm{pH}$ in terms of peak height, peak shape and peak symmetry was found to be 3.0 (Figure 7). Hence, 3.0 were chosen as optimized $\mathrm{pH}$ for the determination.

The plot between peak potential and $\mathrm{pH}$ was linear and the corresponding linearity could be expressed as (Figure 8):

$$
\text { Ep }(\mathrm{V})=-0.058 \mathrm{pH}-1.213 \mathrm{r}^{2}=0.986
$$

A slope value of $58 \mathrm{mV}$ is quite close to the theoretical value of $60 \mathrm{mV}$ per unit $\mathrm{pH}$ value in the given $\mathrm{pH}$ range for a $2 \mathrm{e}^{-} / 2 \mathrm{H}^{+}$or $4 \mathrm{e}^{-} / 4 \mathrm{H}^{+}$electrode process ${ }^{22,23}$.

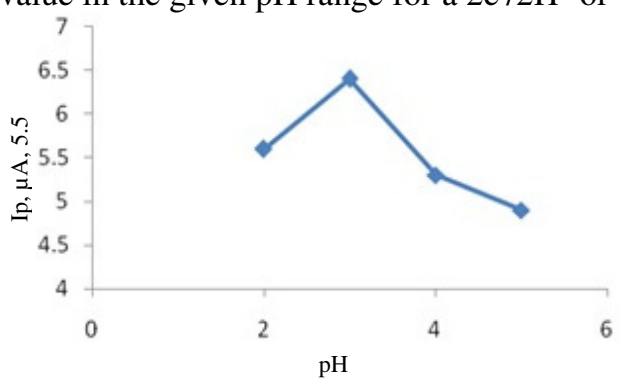

Figure 7. Optimization of $\mathrm{pH}$

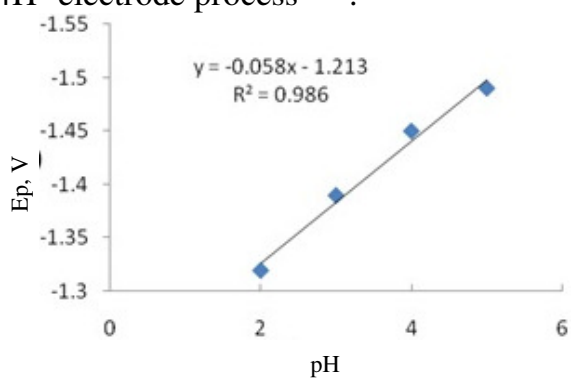

Figure 8. Plot of peak potnetial $\left(\mathrm{E}_{\mathrm{p}}\right)$ versus $\mathrm{pH}$ of $2.5 \times 10^{-4} \mathrm{M}$ CYP solution 


\section{Proposed reduction mechanism}

Based on the $\mathrm{pH}$ studies and CPC studies the overall reduction may be termed to be $2 \mathrm{e}^{-} / 2 \mathrm{H}^{+}$ reduction process. Hence a reduction mechanism was proposed following all the experimental observations (Scheme 1).

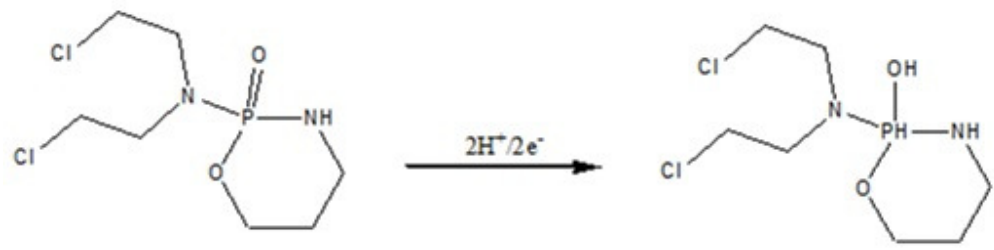

Scheme 1. Proposed reduction mechanism of CYP

\section{Electroanalytical determination of CYP}

Voltammetric methods are widely being used for analytical purposes due to its cost effectiveness, high sensitivity, accuracy, precision and involvement of quite simple steps for analysis. In present paper, Differential pulse Cathodic adsorptive stripping voltammetric methods was optimized for determination of CYP in bulk form, pharmaceutical formulations and in human urine using glassy carbon electrode. All parameters were optimized prior to the determination of drug (Table 1) in order to attain best peak response in terms of peak height and peak shape.

\section{Optimization of parameters}

The response to the applied potential depends on various operational parameters such as scan increment $(\Delta \mathrm{S})$, accumulation time $\left(\mathrm{t}_{\mathrm{acc}}\right)$, accumulation potential $\left(\mathrm{E}_{\mathrm{acc}}\right)$, pulse amplitude $\left(\mathrm{E}_{\mathrm{sw}}\right)$, peak to peak amplitude, pulse period and pulse width etc. All operational parameters were examined to optimize so as best peak response in terms of peak shape, peak height, and peak stability could be obtained. The optimized parameters are given in Table 1.

Table 1. The optimized experimental parameters for DP-CAdSV procedure for the determination of Cyclophosphamide

\begin{tabular}{cc}
\hline Optimized operational parameters & \\
\hline Scan increment, $\mathrm{mV}$ & 04 \\
Pulse amplitude, $\mathrm{mV}$ & 25 \\
Deposition time, $\mathrm{s}$ & 15 \\
Deposition potential, $\mathrm{V}$ & -0.1 \\
Pulse width, $\mathrm{s}$ & 0.2 \\
Pulse period, $\mathrm{s}$ & 0.5 \\
\hline
\end{tabular}

DPCAdSV (Differential pulse cathodic adsorptive stripping voltammetry)

\section{Effect of concentration}

The linear variation of peak current with respect to concentration was examined and a linearity range was established by plotting a graph between $\mathrm{I}_{\mathrm{p}}$ and concentrations. The linearity range for DPCAdSV was found to be within the range $5.0 \times 10^{-5}-1.75 \times 10^{-4} \mathrm{M}$. Figure 9 and 10 shows the recorded differential pulse cathodic adsorptive stripping voltammograms of CYP with varying concentrations and corresponding calibration curve respectively.

The linear regression equation for the plot between $\operatorname{Ip}(\mu \mathrm{A})$ versus concentration $(\mathrm{M})$ for DPCAdSV as depicted in Figure 10 is written as:

$$
\operatorname{Ip}(\mu \mathrm{A})=1.8627 \mathrm{E}+04 \text { Conc }(\mu \mathrm{A} / \mathrm{M})+0.204(\mu \mathrm{A}) \mathrm{r}^{2}=0.997
$$




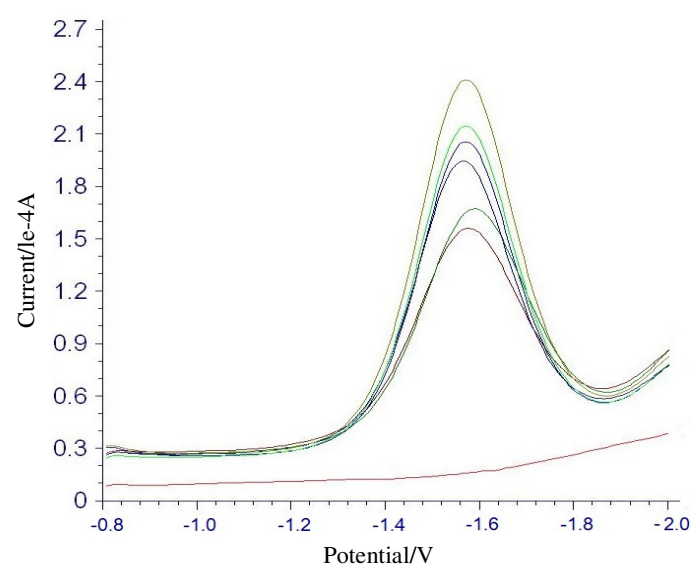

Figure 9. The DP-CAdS voltammogram of CYP at different concentrations in bulk form in BR buffer at $\mathrm{pH} 3.0$

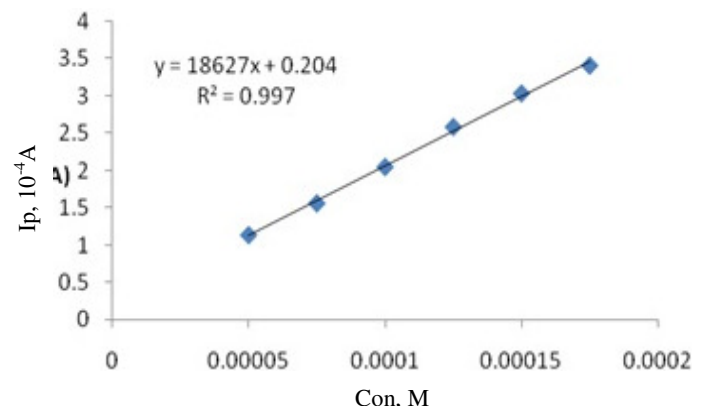

Figure 10. Plot of peak current $\left(\mathrm{I}_{\mathrm{p}}\right)$ versus concentration $(\mathrm{C})$ from voltammogram in Figure 9 of CYP with varying concentrations in BR Buffer of $\mathrm{pH} 3.0$

\section{Validation of analytical procedure}

The proposed method was validated for determination of cyclophophamide in bulk form by determining various elements viz. linearity range of concentration, limit of detection (LOD), limit of quantification (LOQ), \% Recovery, Ruggedness and Robustness.

\section{Limit of detection (LOD) and Limit of quantification}

Detection limit was calculated as LOD $=3 \mathrm{~S} / \mathrm{m}$ and limit of quantification was calculated using equation $\mathrm{LOQ}=10 \mathrm{~S} / \mathrm{m}$ where, $\mathrm{s}$ is the standard deviation of intercept of calibration curve and $\mathrm{m}$ is the slope of the related calibration curve ${ }^{24-26}$. Low values of detection and quantification limits indicated about the good sensitivity of the proposed method. Similarly, low value of \% RSD indicates less spread of sets of data that is a good precision in the method. All data are tabulated in Table 2.

\section{Accuracy and precision}

Following the linearity range of the developed method (DPCAdSV) using GCE, accuracy and precision were examined by adding certain amount from the standard solution of CYP and finding corresponding \% recoveries. Nearness of the found amount to the true added amount indicated about the good accuracy and a low \%RSD ( $\mathrm{n}=5)$ for measurements showed a great precision of the developed method (Table 3 ). 
Table 2. Analytical parameters for voltammetric determination of CYP in bulk form using DPCAdSV at bare GCE

\begin{tabular}{cc}
\hline \multicolumn{2}{c}{ DPCAdSV } \\
\hline Parameters & Results \\
\hline Measure potential, V & -1.4 \\
Linearity range, $\mathrm{M}$ & $5.0 \times 10^{-5}-1.75 \times 10^{-4}$ \\
Slope, $\mu \mathrm{A} / \mathrm{mol} / \mathrm{L}$ & $1.86 \times 10^{4}$ \\
Intercept, $\mu \mathrm{A}$ & 0.204 \\
Correlation coefficient & 0.997 \\
LOD, mol/L & $1.1 \times 10^{-6}$ \\
LOQ, mol/L & $3.67 \times 10^{-6}$ \\
SD & 0.00683 \\
Repeatability, \%RSD & 2.04
\end{tabular}

LOD, limit of detection; $L O Q$, limit of quantification; DPCAdSV, differential pulse wave cathodic adsorptive stripping voltammetry; $R S D$, relative standard deviation; $S D$, standard deviation

Table 3. Result of accuracy for assay of CYP in Bulk form using DPCAdSV at GCE

\section{DPCAdSV}

\begin{tabular}{ccccc}
\hline S.No. & Amount added, mg/L & "Mean recovery & SD & \%RSD \\
\hline 1 & 15 & $15.014 \pm 0.07$ & 0.056 & 0.37 \\
2 & 30 & $30.028 \pm 0.092$ & 0.074 & 0.25 \\
3 & 45 & $45.052 \pm 0.07$ & 0.056 & 0.12 \\
\hline
\end{tabular}

*The data were collected based on the five separate $(n=5)$ determinations. Average for five determination process and recovery values are given as mean \pm ts/ $/ n$ (at $95 \%$ confidence level)

Application of analytical determination to spiked human urine samples

The expediency of the method was evaluated by applying it for the determination of CYP in spiked urine as biological sample. No pretreatment such as time-consuming extraction or evaporation step was required for sample preparation. The proposed method can be applied after a simple dilution step with direct measurements, keeping the media acidic. The results of analysis for spiked urine are given in Table 4 and Table 5.

Table 4. Recovery results of proposed method for spiked human urine samples (solution of standard CYP was spiked)

\begin{tabular}{ccccc}
\hline Sample & $\begin{array}{c}\text { Amount } \\
\text { added, mg/L }\end{array}$ & $\begin{array}{c}\text { Amount found, } \\
\mathrm{mg} / \mathrm{L}\end{array}$ & Recovery $^{\mathrm{a}}$ & \%RSD $^{\text {DPCAdSV }}$ \\
\hline $\begin{array}{c}\text { Standard in } \\
\text { urine sample }\end{array}$ & 25 & 25.34, & $\begin{array}{c}25.308 \pm 0.34 \\
\mathrm{t}_{\text {cal }}=2.54\end{array}$ & 1.07 \\
$\mathrm{t}_{\mathrm{tab}}=2.78$ & & \\
\hline
\end{tabular}

${ }^{a}$ Results of recovery values are given as mean \pm ts/ $\checkmark n$ (at $95 \%$ confidence level).

Table 5. Recovery results of proposed method for spiked human urine samples (solution of cyphos was spiked)

\begin{tabular}{ccccc}
\hline Sample & $\begin{array}{c}\text { Amount } \\
\text { added, mg/L }\end{array}$ & $\begin{array}{c}\text { Amount found, } \\
\mathrm{mg} / \mathrm{L}\end{array}$ & Recovery $^{\mathrm{a}}$ & \%RSD \\
\hline & & DPCAdSV & $15.27 \pm 0.41$ & \\
$\begin{array}{c}\text { Cyphos in } \\
\text { urine sample }\end{array}$ & 15 & $15.33,15.43,15.65,14.77,15.12$ & $\begin{array}{c}\mathrm{t}_{\mathrm{cal}}=1.83 \\
\mathrm{t}_{\mathrm{tab}}=2.78\end{array}$ & 2.16 \\
\hline
\end{tabular}

${ }^{a}$ Results of recovery values are given as mean \pm ts/ ${ }_{\Downarrow} n$ (at $95 \%$ confidence level) 


\section{Conclusion}

In this study electrochemical reduction behavior of CYP was studied on glassy carbon electrode. The reduction was found to be one step, irreversible and diffusion controlled in rate determining step. The detailed kinetic behavior was studied which in turn helped in deducing its mechanism of action. Differential pulse cathodic adsorptive voltammetric method was optimized for the voltammetric determination of CYP in bulk form and in human urine as biological sample.

Proposed and validated voltammetric method provides a fast, sensitive, cost-effective and a quite simple approach to the determination of CYP in bulk form and spiked human urine samples. Furthermore, the method had lower detection limit and showed good accuracy, precision, repeatability and selectivity to the determination process, hence making it cheap and reliable technique.

\section{Acknowledgment}

This work was financially supported by the Council of Scientific and Industrial Research, New Delhi, India, by grant File Number 09/149(0654)/2014/EMR-I.

\section{References}

1. Pryor B D, Bologna S G and Kahl L E, Arthritis Rheumatism., 1996, 39(9), 14751482; DOI:10.1002/art.1780390906

2. Shanafelt T D, Lin T and Geyer S M, Cancer, 2007, 109(11), 2291-2298; DOI:10.1002/cncr.22662

3. Nicolini A, Mancini P and Ferrari P, Anselmi L, Tartarelli G, Bonazzi V, Carpi A and Giardino R, Biomedicine Pharmacotherapy, 2004, 58(8), 447-450; DOI:10.1016/j.biopha.2004.08.006

4. Hall A G and Tilby M J, Blood Reviews, 1992, 6(3), 163-173; DOI:10.1016/0268960X(92)90028-O

5. Tilby M J, Lawley P D and Farmer P B, Chemico-Biological Interactions, 1990, 73(2-3), 183-194; DOI:10.1016/0009-2797(90)90002-5

6. Brookes P and Lawley P D, Biochemical Journal. 1961, 80(3), 496-503; DOI:10.1042/bj0800496

7. Steinberg A D, Kaltreider H B, Staples P J, Goetzl E J, Talal N and Decker J L, Annals Internal Medicine, 1971, 75(2), 165-171.

8. Palaska P, Aritzoglou E and Girousi S, Talanta, 2007, 72(3), 1199-1206; DOI:10.1016/j.talanta.2007.01.013

9. Huang B, Xiao L, Dong H, Zhang X, Gan W, Mahboob S, Al-Ghanim K A, Yuan Q and Li Y, Talanta, 2017, 164, 601-607; DOI:10.1016/j.talanta.2016.11.009

10. Malothu N, Veldandi U K and Devarakonda R K, Asian J Pharm Clin Res., 2010, 3(3), 197-200.

11. Martins I, Rosa H V D and Apostoli P, Revista Brasileira de Ciências Farmacêuticas, 2004, 40(1), 67-73.

12. Murnane D, Martin G P and Marriott C, J Pharm Biomed Anal., 2006, 40(5), 11491154; DOI:10.1016/j.jpba.2005.09.028

13. Mohamed Z H, Amer S M and El-Kousasy A M, J Pharm Biomed Anal., 1994, 12(9), 1131-1136.

14. Mohamed Z H, Amer S M, El-Kousasy A M and Amer M M, Anal Lett., 1995, 28(4), 635-647; DOI:10.1080/00032719508001123 
15. Nicholson R S, Anal Chem., 1965, 37(11), 1351-1355; DOI:10.1021/ac60230a016

16. Gosser D K, Cyclic Voltammetry: Simulation and Analysis of Reaction Mechanisms, VCH, New York, 1994.

17. Muñoz E, Camacho L, Avila J L and Blanco F G, Analyst, 1989, 114, 1611-1615; DOI:10.1039/AN9891401611

18. Elqudaby H M, Gehad G Mohamed, F A. Ali and Sh M. Eid, Arab J Chem., 2013, 6(3), 327-333; DOI:10.1016/j.arabjc.2011.05.019

19. Goyal R N, Rana A R, Aziz M A and Oyama M, Anal Chim Acta, 2011, 693(1-1), 3540; DOI:10.1016/j.aca.2011.03.026

20. Niu X, Yan L, Wen Z, Li X, Niu Y, Lu Y and Sun W, Anal Lett., 2017, 50(2), 325335; DOI:10.1080/00032719.2016.1177536

21. Bard A J and Faulkner L R, Electrochemical Methods: Fundamentals and Applications, 2 ${ }^{\text {nd }}$ Ed., John Wiley and Sons Inc, New York, 2006.

22. Tasdemir I H, Akay M A, Erk N and Kilic E, Electroanalysis, 2010, 22(17-18), 2101-2109; DOI:10.1002/elan.201000100

23. Jain R and Sharma R, J Electrochem Soc., 2013, 160(8), 489-493; DOI:10.1149/2.105308jes

24. Sinha P, Shekhawat A and Sharma D K, Rep Electrochem., 2015, 5, 21-28; DOI:10.2147/RIE.S90750

25. Jain R and Sharma S, J Pharm Anal., 2012, 2(1), 56-61; DOI:10.1016/j.jpha.2011.09.013

26. Jhankal K K, Sharma A, Ramswaroop and Sharma D K, J Pharma Sci Res., 2015, 7(1), 10-16. 